\title{
Gonadotropin characterization, localization and expression in the European hake (Merluccius merluccius)
}

\author{
Michela Candelma ${ }^{1}$, Romain Fontaine ${ }^{2}$, Sabrina Colella ${ }^{3}$, Alberto Santojanni ${ }^{3}$, \\ Finn-Arne Weltzien ${ }^{2}$ and Oliana Carnevali ${ }^{1}$ \\ ${ }^{1}$ Department of Life and Environmental Sciences, Università Politecnica delle Marche, Ancona, Italy, ${ }^{2}$ Department of \\ Basic Sciences and Aquatic Medicine, Norwegian University of Life Sciences, Oslo, Norway, and ${ }^{3}$ CNR-National \\ Research Council of Italy, ISMAR-Marine Sciences Institute, Ancona, Italy \\ Correspondence should be addressed to O Carnevali; Email: o.carnevali@univpm.it
}

\begin{abstract}
In vertebrates, the regulation of gametogenesis is under the control of gonadotropins (Gth), follicle-stimulating hormone (Fsh) and luteinizing hormone (Lh). In fish, the physiological role of Gths is not fully understood, especially in species with asynchronous ovarian development. To elucidate the role of Gths in species with asynchronous ovary, we studied European hake (Merluccius merluccius) during the reproductive season. For this aim, we first cloned and sequenced both hormones. Then, we characterized their amino acid sequence and performed phylogenetic analyses to verify the relationship to their orthologues in other species. In addition, the quantification of gene expression during their natural reproductive season was analyzed in wild-caught female hake. Our results revealed that fshb peaked during the vitellogenic phase, remaining high until spawning. This is in contrast to the situation in species with synchronous ovary. Ihb, on the other hand, peaked during maturation as it is also common in species with synchronous ovarian development. Finally, combining double-labeling fluorescent in situ hybridization (FISH) for Gth mRNAs with immunofluorescence for Lh protein, we evidenced the specific expression of $f s h b$ and $/ h b$ in different cells within the proximal pars distalis (PPD) of the pituitary. In addition to gonadotrope cells specific to expression of either fshb or $\mathbf{l} \boldsymbol{h} b$, some cells showed co-expression of both genes. This suggests either that gonadotropes with co-expression are not yet specified or they could have a plasticity that permits changes from one cell phenotype to another during certain life stages and in turn during different physiological states.

Reproduction (2017) 153 123-132
\end{abstract}

\section{Introduction}

The pituitary gonadotropins, follicle-stimulating hormone (Fsh) and luteinizing hormone (Lh) are hormones directly involved in regulation of gametogenesis in vertebrates (Nagahama 1994, Swanson et al. 2003, Weltzien et al. 2004). Both gonadotropins are heterodimeric glycoproteins and consist of a common $\alpha$ subunit shared with thyroid-stimulating hormone (Tsh) and a hormonespecific $\beta$ subunit important for their biological specificity.

Fsh and Lh are secreted by gonadotropes present mainly in proximal pars distalis (PPD) and some cells of pars intermedia (PI) of the pituitary gland in teleosts (Weltzien et al. 2003a). In mammals, the gonadotrope cells produce both gonadotropins (Nakane 1970) and rarely an overlapped expression was found. On the contrary, in teleosts, Fsh and Lh are synthesized by two different cell types (Zohar et al. 2010) and the colocalization of the two mRNAs in the same gonadotrope cell was only occasionally evidenced (García Hernández et al. 2002, Weltzien et al. 2014).

Because of the variety of reproductive strategies in different teleost species, the physiological roles of the two gonadotropins during the ovarian cycle do not seem to be the same for all species. Following Tyler and Sumpter (1996), reproductive strategies can be differentiated on the basis of the dynamics of ovarian development: ovaries can be classified as synchronous or asynchronous, even though such division could be reductive due to the wide number of reproductive strategies. The species with synchronous ovaries spawn eggs once within the reproductive season. These species are characterized by increasing plasma levels of Fsh with ovarian development (Tyler et al. 1997), whereas Lh surges during final maturation and spawning (Planas \& Swanson 1995, Gomez et al. 1999, Yoshiura et al. 1999, Schmitz et al. 2005).

The regulatory mechanism of gonadotropins during gametogenesis is not so clear when we consider the teleosts with asynchronous ovaries, i.e., the species that spawn multiple batches of oocytes during the reproductive season. For instance in chub mackerel (Scomber japonicus), fshb mRNA levels increase during the first stages of ovarian cycle, peaking at the end of vitellogenesis, whereas I $h b \mathrm{mRNA}$ levels significantly increase during late vitellogenesis. Finally, the mRNA levels for both hormones 
significantly decrease during post-spawning (Nyuji et al. 2012). Also in other multiple batch spawners as Sparus aurata (Gen et al. 2000), Dicentrarchus labrax (Mateos et al. 2003), Hippoglossus hippoglossus (Weltzien et al. 2003b), Anguilla japonica (Han et al. 2003) and Paralichthys olivaceus (Kajimura et al. 2001) both hormones show the same fluctuation during gonadal cycle. Unlike these results, in the Atlantic cod (Gadus morhua), a multiple batch spawner, two peaks of $f_{s} h b$ were observed, the highest before spawning and the second during spawning time together with /hb (Mittelholzer et al. 2009).

For this purpose, the current study was aimed to better understand the functions of Fsh and Lh in the reproduction of European hake, a species with asynchronous ovarian development characterized by different phases of maturation (Sarano 1986, Murua et al. 1998). In the present study, the endocrine control of ovarian maturation of European hake was approached for the first time, by studying gonadotropin molecular characterization, expression and localization in the pituitary gland throughout the seasonal reproductive cycle in wild specimens captured in the Adriatic Sea.

\section{Materials and methods Monthly sampling}

During 2015, a total number of 129 European hake females were collected on board of bottom trawler fishing vessel in the Northern and Central Adriatic Sea (FAO-Geographical Sub-Area 17, according to GFCM division). The specimens were collected under the guidelines of the Data Collection Framework Regulation (EU Reg.199/2008) that established a Community system for the conservation and sustainable exploitation of fisheries resources under the Common Fisheries Policy (CFP). The procedures did not include animal experimentation, and ethics approval is not necessary in accordance with the Italian legislation. We considered fish animals in a length range of $28-35 \mathrm{~cm}$ that were macroscopically and microscopically classified in five different ovarian classes: immature/regenerating (F1); developing (F2); spawning capable (F3A); actively spawning (F3B), and spent, postspawning (F4) (Table 1), following the ovarian classification of
Table 1 Criteria used to determine maturational status of European hake females.

\begin{tabular}{|c|c|c|}
\hline & Phase & Ovarian morphology \\
\hline $\mathrm{F} 1$ & $\begin{array}{l}\text { Immature/regenerating } \\
\text { (inactive) }\end{array}$ & Orange, semi-transparent \\
\hline $\mathrm{F} 2$ & Developing & Small pink but some oocytes visible \\
\hline $\mathrm{F} 3 \mathrm{~A}$ & Spawning capable & $\begin{array}{l}\text { Large ovaries, oocytes visible } \\
\text { macroscopically }\end{array}$ \\
\hline F3B & Actively spawning & Abundance of hydrated oocytes \\
\hline $\mathrm{F} 4$ & $\begin{array}{l}\text { Spent, regression, } \\
\text { post-spawning }\end{array}$ & $\begin{array}{l}\text { Small ovaries, blood vessels } \\
\text { reduced but present. }\end{array}$ \\
\hline
\end{tabular}

Brown-Peterson and coworkers (2011), but adapted for European hake. The brief post-spawning phase makes difficult the sampling of class $\mathrm{F} 4$ females, consequently only classes F1, $\mathrm{F} 2, \mathrm{~F} 3 \mathrm{~A}$ and $\mathrm{F} 3 \mathrm{~B}$ are included in this work. For the molecular analysis, we considered the animals sampled when the highest values of gonadosomatic indices (GSI) were recorded during the year. The pituitary glands for $\mathrm{qPCR}$ analyses were immediately preserved in RNAlater (Ambion) and stored at $-20^{\circ} \mathrm{C}$ until further analysis. Pituitary glands for fluorescent in situ hybridization (FISH) and immunofluorescence techniques were fixed in $4 \%$ paraformaldehyde (PFA) in PBST (PBS with $0.1 \%$ Tween $20, \mathrm{pH}=7.4$ ) and then dehydrated in increasing concentrations of ethanol before being preserved in pure methanol at $-20^{\circ} \mathrm{C}$ until further processing. Body and gonad weights were recorded to calculate the gonadosomatic index (GSI): GSI (\%) = gonad weight $\times 100 /$ gutted weight. Pieces of ovarian tissue from females collected in different maturity stages were fixed in 4\% PFA for histological processing to confirm macroscopic classification of gonad development.

\section{RNA extraction, cloning and sequencing of cDNA for European hake fshb and lhb}

Total RNA was extracted from twenty pituitary glands using TRIzol Reagent, following the manufacturer's protocol (Invitrogen Life Technologies). One total RNA was used for cDNA synthesis, employing iScript cDNA Synthesis Kit (Bio-Rad Laboratories). mRNA sequences for $f_{s} h b$ and $/ h b$ were amplified using primers designed by Primer3 (http:// bioinfo.ut.ee/primer3/) after alignment (ClustalW2 software, at EMBL-EBI, Cambridge, UK) with sequences from other teleost species to localize well-conserved regions (Table 2).

Table 2 Primer sequences of European hake used for $5^{\prime}$ - and 3'-RACE and qRT-PCR.

\begin{tabular}{llll}
\hline Name & Sequence $\left(5^{\prime}-3^{\prime}\right)$ & Orientation & Usage \\
\hline 3' RACE universal primer & 5'-CGCGGATCCGAATTAATACGACTCACTATAGG-3' & Reverse & $3^{\prime}$-RACE primer \\
5' RACE universal primer & 5'-CGCGGATCCGAACACTGCGTTTGCTGGCTTTGATG-3' & Forward & 5'-RACE primer \\
bact & 5'-GTCATGGACTCCGGTGATGG-3' & Forward & qPCR \\
fshb & 5'-GAGGTAGTCTGTGAGGTCGC-3' & Reverse & qPCR \\
& 5'-ATGCAGCTGGTTGTCATGG-3' & Forward & $3^{\prime}$-RACE primer \\
& 5'-TGCTCTGACACAGGGAACAC-3' & Reverse & 5'-RACE primer \\
Ihb & 5'-TCTGTCGCCCAGTCAACTTC-3' & Forward & qPCR \\
& 5'-CCCACCGGACAGTCTTCAAA-3' & Reverse & 9PCR \\
& 5'-GTGGAGACCACCATCTGCA-3' & Forward & 3'-RACE primer \\
& 5'-CAGCGGACACTGCATCAC-3' & Forward & qPCR \\
\hline
\end{tabular}

bact, $\beta$-actina; fshb, follicle-stimulating hormone beta subunit; Ihb, luteinizing hormone beta subunit; RACE, rapid amplification of cDNA ends. 


\begin{tabular}{|c|c|}
\hline A EhFSH & VCRPYNFTINVT-SCDKHRS IVTTICEGQCYQMDP IYK-- \\
\hline AcFSH & $--------M Q L V V M A A V L-A M T W A D Q P C S$ \\
\hline EsbFSH & $--------M Q L V V M$ \\
\hline AhFSH & $--------M Q L V V M$ \\
\hline ZfFSH & $------M R M R V L V L$ \\
\hline CSFSH & MYCTHLMTLQLVVM \\
\hline JeFSH & ----- MHLAVTAL \\
\hline hFSH & $-------\mathrm{MKSLQFCFLF---CCWKAIC}$ \\
\hline EhFSH & N-GDWSYETKHFEDCPVGF----SYE \\
\hline $\mathrm{ACFSH}$ & S-GDWAYEVKHFEGC̄LEGV----LYPV \\
\hline EsbFSH & 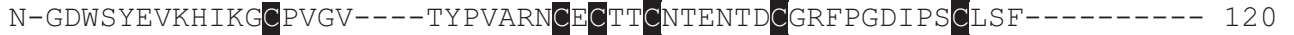 \\
\hline AhFSH & SICNLDDTDCSPFPGDIPGCLTTLHSLSLSTLD 131 \\
\hline ZfFSH & NEKNLMYKSYEFKGCPAGVDSVFVYPV \\
\hline CSFSH & NEKEWSYEKVYLEGCPSGVEPFF-IPV \\
\hline JeFSH & NFRDVVYETVHLPGCPSGMDLHFTYPVA \\
\hline hFSH & TFKELVYETVKVPGCAAHHADSLYTYPVAT \\
\hline
\end{tabular}

B EhLH

AcT

EsbLH

AhLH

$\mathrm{ZfLH}$

$\mathrm{CsLH}$

$\mathrm{JeLH}$

$\mathrm{hLH}$

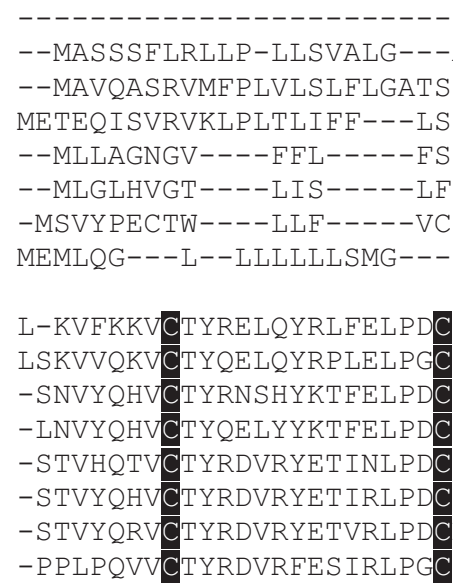

-VETTI

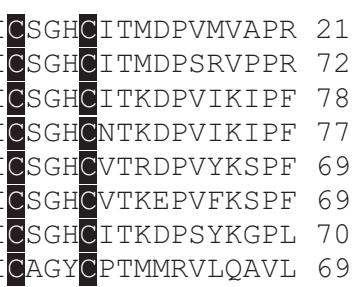

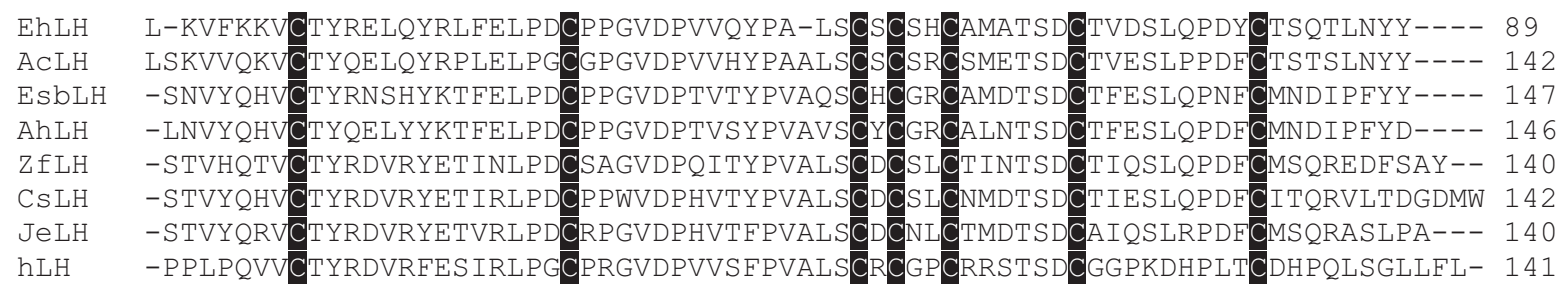

Figure 1 Amino acid sequence alignments of beta subunits of follicle-stimulating hormone, Fshb (A) and luteinizing hormone, Lhb (B) of European hake and other fishes. The cysteine residues are highlighted and potential $\mathrm{N}$-glycosylation sites are shaded. The sequences were extracted from GenBank databases and their abbreviation and accession numbers are Merluccius merluccius (Eh KX377614, KX377615), Gadus morhua (Ac: ABD62883, ABD62884), Dicentrarchus labrax (Es: AAN40506, AAN40507), Danio rerio (Zf: AAV31152, AAV31153), Anguilla japonica (Je: Q9YGK3, BAD14302), Oncorhynchus keta (Cs: AAA49408, AAA49409), Hippoglossus hippoglossus (Ah: CAD10501, CAD10502) and human (P01228, P01229).

PCR amplifications were run using annealing temperatures between 52 and $62^{\circ} \mathrm{C}$ and $1 \mathrm{~min}$ extension time on an iCycler Thermocycler (Bio-Rad). Each gene product was cloned into the pGEM-T Easy vector system (Promega) in accordance with the manufacturer's protocol. From the obtained partial sequences, 5'-RACE and 3'-RACE (rapid amplification of cDNA ends) primers were designed (Table 2). When a single band was obtained following RACE PCR, it was isolated and cloned. All the cloned inserts were sequenced by BMR Genomics of Padova (Italy).

\section{Protein prediction, identification and multiple alignments}

Primary structures were predicted and characterized by Webbased bioinformatics tools such as ExPASy Translate (http:// web.expasy.org/translate/), ORF Finder (http://www.ncbi. nlm.nih.gov/projects/gorf/), the BLAST suite (http://blast.ncbi. nlm.nih.gov/Blast.cgi). The open reading frames were aligned with Clustal Omega v. 1.2.1 (Sievers et al. 2011 - http://www. ebi.ac.uk/Tools/msa/clustalo/) from the Multiple Sequence
Alignment tools provided by the EBI website. Gonadotropins were aligned with MUSCLE v. 3.8 (Edgar 2004 - http://www. ebi.ac.uk/Tools/msa/muscle/). The printing and shading of the alignment files were obtained with BOXSHADE v. 3.21 (http://www.ch.embnet.org/software/BOX_form.html), with a consensus threshold set at 0.5 to be represented by symbols.

\section{Real-time PCR}

qPCRs were performed with the SYBR green method in an iQ5 iCycler thermal cycler (Bio-Rad). Triplicate PCRs were carried out for each sample analyzed following Santangeli and coworkers (2016). Beta-Actin (bact) was used as housekeeping gene to standardize the results by eliminating variation in mRNA and cDNA quantity. As shown in Raingeard and coworkers (2009), the bact was chosen like reference gene because the mRNA levels were close to those of our target genes and the levels did not vary through different stages of reproduction. No amplification product was observed in non-template controls and no primer-dimer formations were observed in the control samples. The data obtained were analyzed using the 


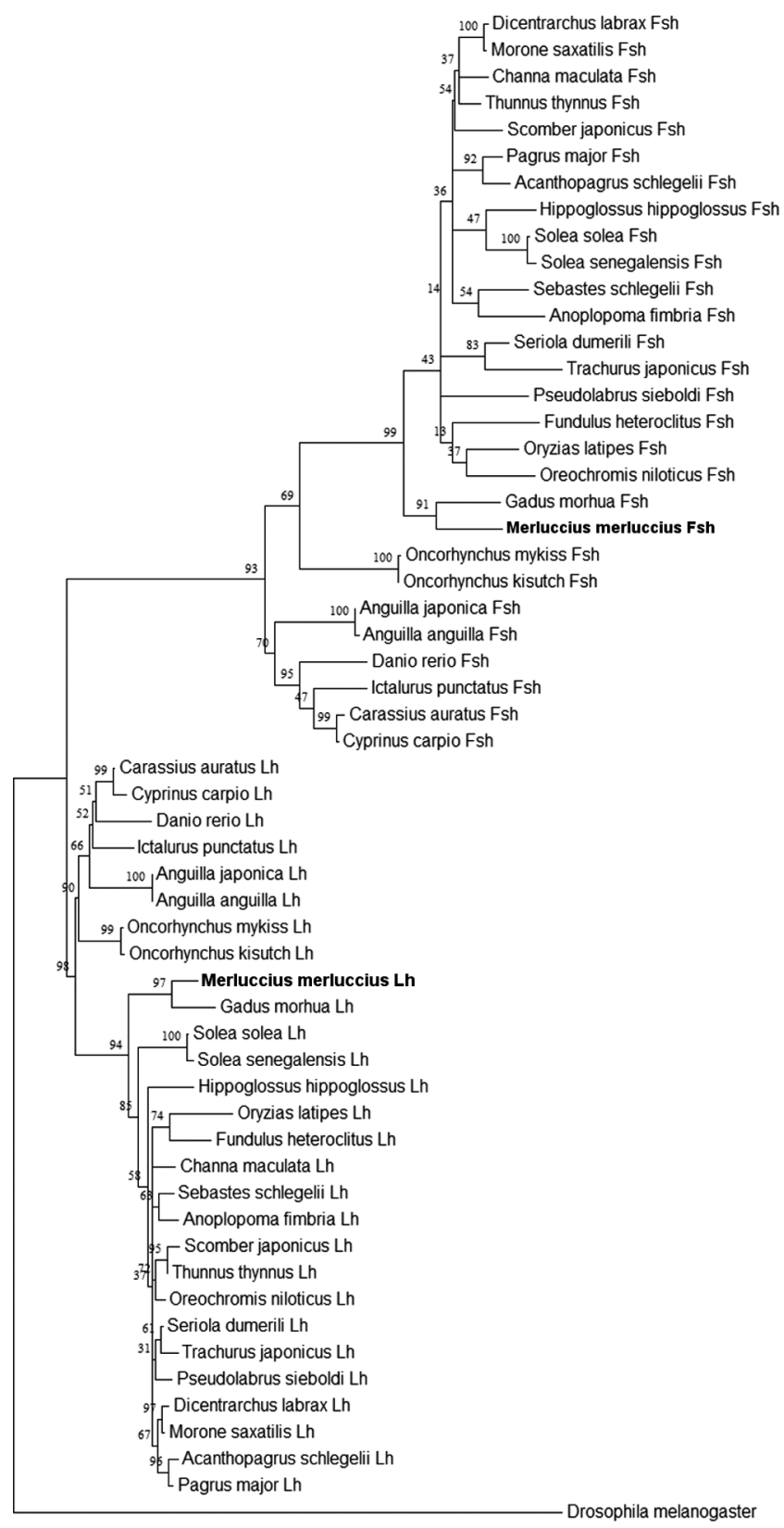

0.5

Figure 2 Phylogenetic comparison of fish full-length folliclestimulating hormone (Fshb) and luteinizing hormone (Lhb) amino acid sequences. The analysis was performed by MEGA6 using maximum likelihood and default settings. A rooted consensus phylogenetic tree generated by means of the Neighbor-Joining algorithm, glycoprotein hormone beta subunit-related protein of $D$. melanogaster as outgroup. Bootstrap values from 1000 replicates are indicated for each tree node. Gene bank accession numbers: Merluccius merluccius (KX377614; KX377615); Gadus morhua (ABD62883; ABD62884); Dicentrarchus labrax (AAN40506; AAN40507); Acanthopagrus schlegelii (ADX31689; ADX31690); Pagrus major (BAB18563; BAB18564); Channa maculata (AAS01610; AAS01609); Seriola dumerili (BAR79709; BAR79710); Hippoglossus hippoglossus (CAD10501; CAD10502); Scomber japonicus (AEN14604; AEN14605); Thunnus thynnus (ABP04057; ABP04050); Sebastes schlegelii (AAU14141; AAU14142); Anoplopoma fimbria (AGS55583; AGS55584);
iQ5 optical system software version 2.0 (Bio-Rad) including GeneEx Macro iQ5 Conversion and Genex Macro iQ5 files.

\section{Fluorescence in situ hybridization (FISH)}

RNA probes for European hake $f_{s} h b$ and $/ h b$ were synthesized using pGEM-T easy vector (Promega). Antisense and sense RNA probes were labeled with digoxigenin-11-UTP for $f_{s} h b$ and fluorescein-12-UTP for Ihb (Roche Diagnostics). Probes were purified using Nucleospin RNA clean-UP kit (MachereyNagel, Hoerdt, France). Regarding the tissue preparation, the pituitary glands were separated from brain. After the samples were rehydrated by a descending series of ethanol solutions (75\%, 50\% and 25\% ethanol), they were placed in 3\% agarose and cut $(120 \mu \mathrm{m}$ sagittal sections) with a VT1000S Leica vibratome. FISH was performed according to Fontaine and coworkers (2013). Briefly, tissues were permeabilized by 45-min treatment with proteinase K $(10 \mu \mathrm{g} / \mathrm{mL}$; P6556, Sigma) and prehybridized in hybridization buffer for $4 \mathrm{~h}$ at $65^{\circ} \mathrm{C}$. Hybridization was performed at $65^{\circ} \mathrm{C}$ for $18 \mathrm{~h}$ in hybridization buffer containing a mixture of probes $(150 \mathrm{ng} / \mathrm{mL}$ each). Samples were washed with wash buffer composed of $25 \mathrm{~mL}$ formamide, $12.5 \mathrm{~mL}$ SSC $20 \times, 50 \mu \mathrm{L}$ Tween $20,770 \mu \mathrm{L}$ of $1 \mathrm{M}$ citric acid and water at different concentrations (50\% formamide $/ 50 \%$ $2 \times$ SSC (saline sodium citrate buffer); $2 \times$ SSC; $0.2 \times$ SSC and PBST), treated for 30 min with $3 \% \mathrm{H}_{2} \mathrm{O}_{2}$ to inactivate endogenous peroxidases. They were then incubated overnight at $4^{\circ} \mathrm{C}$ with antibody. For digoxigenin-labeled fshb probe, an anti-digoxigenin peroxidase-conjugated antibody (Roche Diagnostics) and a Cy5-conjugated tyramide (Perkin Elmer) were used. Fluorescein-labeled $/ h b$ probe was recognized by an anti-fluorescein peroxidase-conjugated antibody (Roche Diagnostics) and revealed by a homemade fluoresceinconjugated tyramide. After extensive washes, samples were mounted between slide and coverslip in Vectashield H-1000 Mounting Medium (Vector, Eurobio/Abcys). The sense probes were used for negative control (data not shown).

\section{Combined FISH and immunofluorescence}

To identify the phenotype of /hb-expressing cells in the hake pituitary gland, a triple labeling protocol was achieved by combining two-color FISH and immunofluorescence. After $\mathrm{FISH}$, the sections were incubated for $2 \mathrm{~h}$ at room temperature in a blocking solution (normal goat serum 4\%, dimethyl sulfoxide $1 \%$, Triton $0.3 \%$ in PBST) and subsequently incubated overnight at $4{ }^{\circ} \mathrm{C}$ with a rabbit antibody (1/1000) directed against the b-subunit of medaka Lh (Oryzias latipes). The

Acanthopagrus schlegelii (AAX18926; ABQ96864); Solea solea (ABW81403; AHZ13200); Oryzias latipes (BAK61761; BAK61762); Oreochromis niloticus (AAP49575; AAP49576); Pseudolabrus sieboldi (BAF81900; BAF81901); Trachurus japonicus (AGO59024; AGO59025); Oncorhynchus mykiss (BAB17686; BAB17687); Oncorhynchus kisutch (AAO72299; AAO72300); Carassius auratus (BAA13530; BAA13531); Anguilla japonica (Q9YGK3; BAD14302); Fundulus heteroclitus (P30971; P30972); Cyprinus carpio (CAA42542; CAA42543); Danio rerio (AAV31152; AAV31153); Ictalurus punctatus (AAG32155; AAG32156); Morone saxatilis (AAC38035; AAC38019); Drosophila melanogaster (AAM53262). 


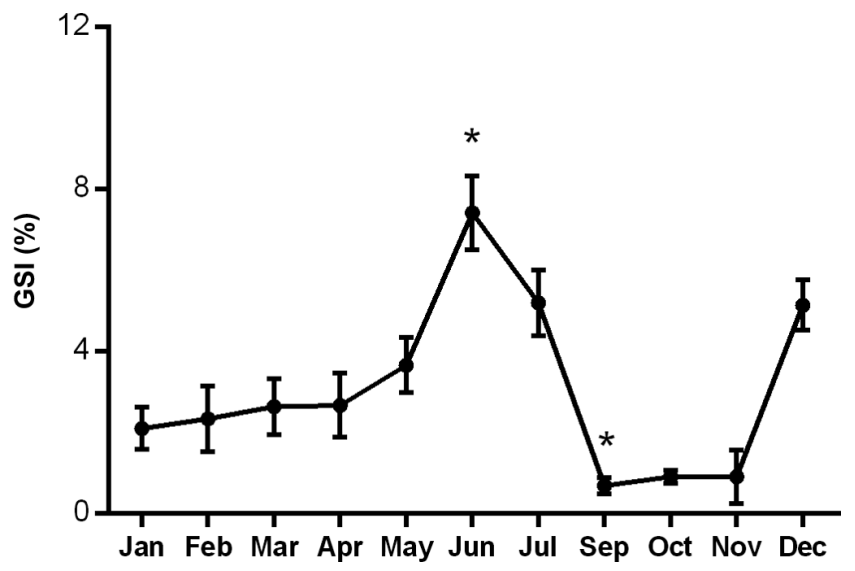

Figure 3 Monthly seasonal variation of European hake females gonadosomatic index (GSI). The asterisks indicate the presence of statistical significance $(P<0.1)$ with respect to previous month. The values are mean \pm S.E.M.

secondary antibody used was a goat antirabbit IgG coupled to DyLight 549 (Jackson ImmunoResearch Europe Ltd). Negative control for the immunofluorescence was verified in section of different part of pituitary gland (data not shown).

\section{Image acquisition and processing}

Fluorescent images were acquired using a Zeiss LSM 710 laser scanning confocal microscope. For fluorescent tyramides used in two-color FISH and for fluorophore-coupled secondary antibodies used in immunofluorescence studies, lasers with a wavelength of 488 (FITC; Alexa-488), 555 (DyLight 549) and 633 (Cy5; Alexa-633) nm respectively were used. Channels were acquired sequentially to avoid cross-talk between the different filters. The focal planes were recorded using Zeiss ZEN 2009 software. Z-projections were obtained using ImageJ software distributed by Fiji (Schindelin et al. 2012). Composites were assembled using Adobe Illustrator CC (Adobe Systems).

\section{Ovarian histological processing}

Female gonads were maintained in $4 \%$ of PFA for fixation overnight and stored in $70 \%$ ethanol until further processing. Analysis of ovarian stages were conducted on histological paraffin sections $(6-7 \mu \mathrm{m}$ thickness) stained by Harris Hematoxylin and Eosin method following Caputo and coworkers (2001) and examined by Zeiss Axioscop light microscopy with phase-contrast optics at a $200 \times$ magnification.

\section{Phylogenetic analysis}

Alignments and similarity matrices were calculated using Basic Local Alignment Search Tool (BLAST). The structure of deduced amino acid sequences of cloned fragments was predicted by comparison with known structures. Phylogenetic analyses of deduced amino acid sequences of Fshb and Lhb for European hake and other fishes were performed by MEGA version 6.0 (Tamura et al. 2013) using maximum likelihood and default settings. A rooted consensus phylogenetic tree

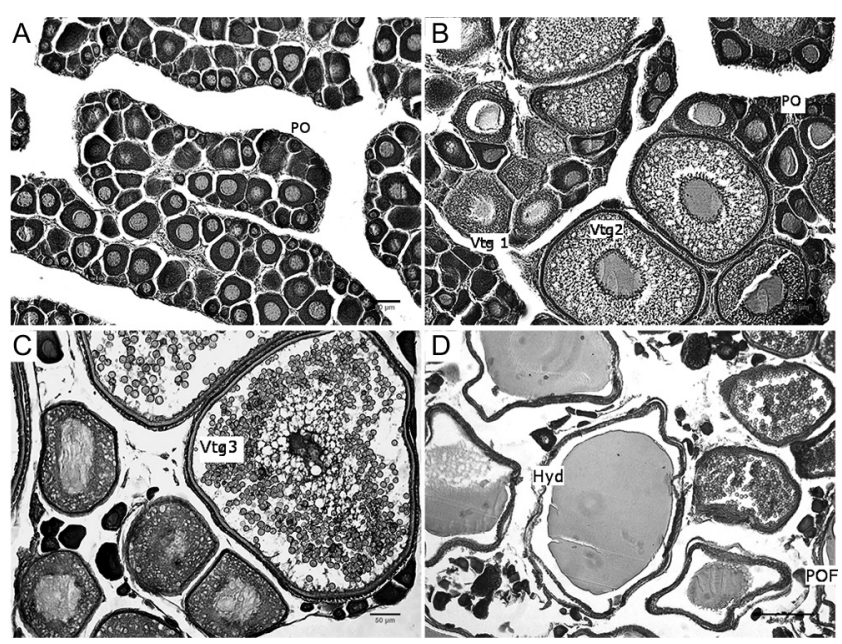

Figure 4 Tissue sections of the ovarian follicles at different developmental stages of European hake females. (A) F1, immature/ regenerating; (B) F2, developing; (C) F3A, spawning capable; (D) F3B, actively spawning. Scale bar $=50 \mu \mathrm{m}$ for A, B, C; scale bar $=100 \mu \mathrm{m}$ for (D). Different stages of ovarian cells were reported in figure. PO, Primary Oocytes (unyolked oocyte); POF, post-ovulatory follicle; Vtg1, Vitellogenin 1; Vtg2, Vitellogenin; Vtg3 Vitellogenin 3; Hydrated oocytes (present only in actively spawning individuals).

was generated by means of the neighbor-joining algorithm, using as outgroup, the glycoprotein hormone beta subunitrelated protein of Drosophila melanogaster for Fsh and Lh. The robustness of the nodes was carried out by a bootstrap analysis from thousand data set replicates.

\section{Statistical analysis}

Results were expressed as the mean \pm S.D. Statistical differences were determined using one-way ANOVA, followed by Bonferroni's multiple comparison test. All statistical analyses were performed using Prism 6 (GraphPad Software). $P$ values $<0.05$ were considered to be significant. Exclusively for GSI data, $P$ values $<0.1$ were considered significant and the results were expressed as the mean \pm S.E.M.

\section{Results}

\section{Molecular characterization of gonadotropin beta subunits}

The European hake cDNA encoding the $f s h b$ consisted of 550 nucleotides with an open reading frame (ORF) of $372 \mathrm{nt}$ and with $5^{\prime}$ and $3^{\prime}$ untranslated regions (UTRs) of 108 and 70 nucleotides respectively (Accession number of GenBank, KX377614). The consensus polyadenylation signal (AATAAA) was $15 \mathrm{nt}$ upstream to the $\operatorname{poly}(A)$ tail. The similarity of $f_{s h b}$ nucleotide sequence of European hake to the sequences of other fishes was in a range from $65 \%$ to $85 \%$. The deduced amino acid sequence of Fshb was 123 amino acid long. In silico analysis of the mature peptide showed a signal peptide of 18 amino acid, two $\mathrm{N}$-linked 

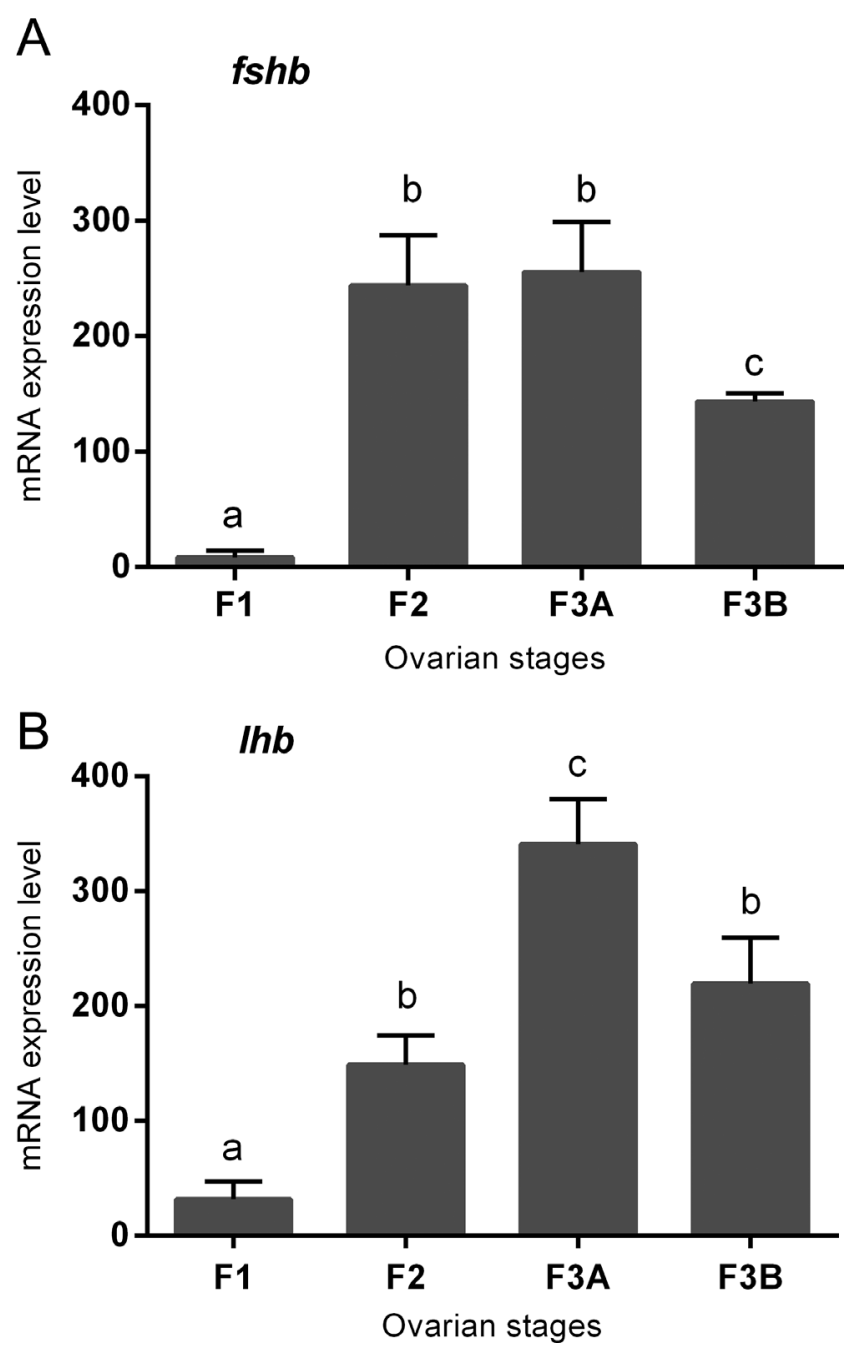

Figure 5 Relative mRNA expression levels of (A) fhsh and (B) Ihb in pituitary gland of European hake in specimens with different ovarian stages. Abundance of $f_{s} h b$ and $/ h b$ transcript was determined by qRT-PCR and normalized with b-actin. The values are mean \pm s.D.

glycosylation sites (NFT) and 12 conserved cysteine residues (Fig. 1). A fragment of lhb of $509 \mathrm{nt}$ was amplified, cloned and sequenced (accession number of GenBank, KX377615). The nucleotide fragment showed high homology with Ihb of other teleosts in a range from $68 \%$ to $82 \%$. The partial deduced amino acid sequence was 89 aa long and although partial, we recognized some conserved clusters, like 9 highly conserved cysteine residues.

\section{Phylogenetic analysis of gonadotropins}

Phylogenetic analyses showed that the vertebrate Gths were divided into Fsh and Lh clusters in the phylogenetic tree rooted using the glycoprotein hormone beta subunitrelated protein of D. melanogaster as outgroup (Fig. 2). The percentage of trees in which the associated taxa clustered together is shown below the branches. Both
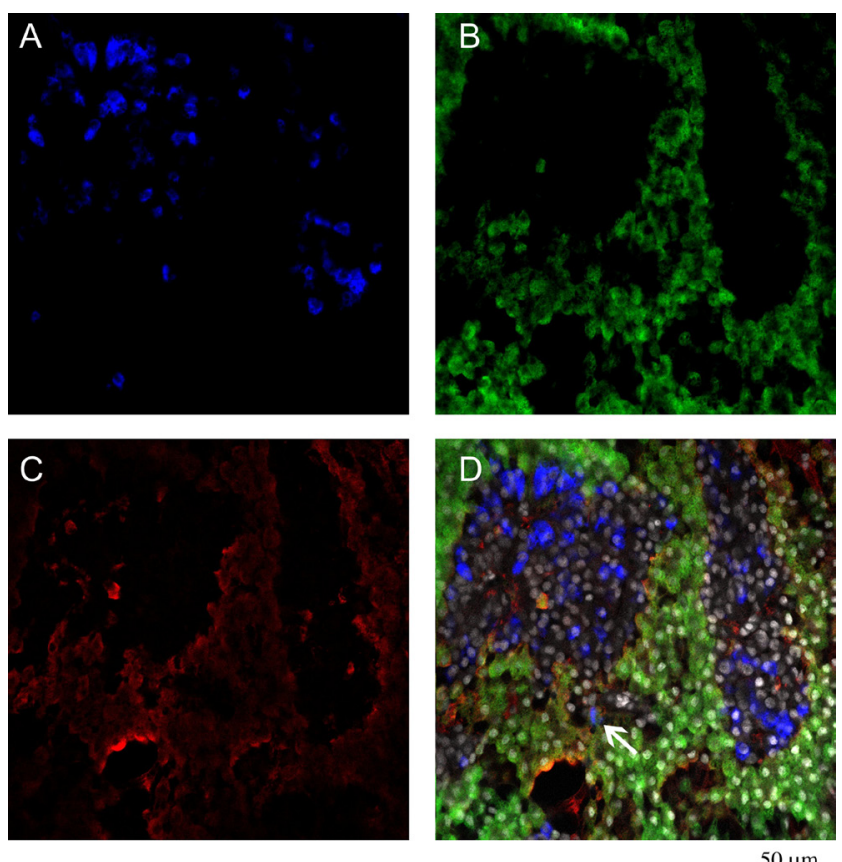

Figure 6 Differential expression of the $f$ sh $b(\mathrm{~A})$, Ihb (B) transcripts and Lh protein $(C)$ in adult European hake pituitary gland. The picture 6D shows the merging of three pictures and the arrow evidences the $f_{s} h b$ and $\mathrm{l} h \mathrm{~h}$ co-expression and the presence of Lh protein in a cell.

gonadotropins of $M$. merluccius are closely associated to gonadotropins of G. morhua (Fig. 2).

\section{Ovarian histology and gonadosomatic index (GSI) variation}

The analysis of GSI of hake females through the year evidenced a significant increase $(P<0.1)$ in June compared to precedent months (Fig. 3 ), suggesting the summer season as reproductive period for this species in Adriatic Sea, whereas the GSI peak in December was not significant compared to other months. The histology confirmed the asynchronous development of oocytes for this species (Fig. 4), meaning that the ovaries exhibit multiple oocyte stages (Fig. 4B, C and D).

\section{Gene expression profile analysis}

In this study, the expression of $f_{s} h b$ and $/ h b$ in the pituitary of females during oocyte maturation was examined by qPCR (Fig. 5). Four stages were analyzed, from immature to actively spawning stages. The mRNA level of $f_{s h} b$ was low in immature phase (F1) and raised in developing phase (F2) $(P<0.05)$. It remained at a high level in spawning capable phase (F3A) and significantly decreased in the last phase considered (F3B) $(P<0.05)$. The levels of thb showed a significant increasing trend with a significant peak at beginning of maturation (F3A) $(P<0.05)$. The $/ h b$ mRNA levels were declined during actively spawning stage $(\mathrm{F} 3 \mathrm{~B})(P<0.05)$ as fhsb. 

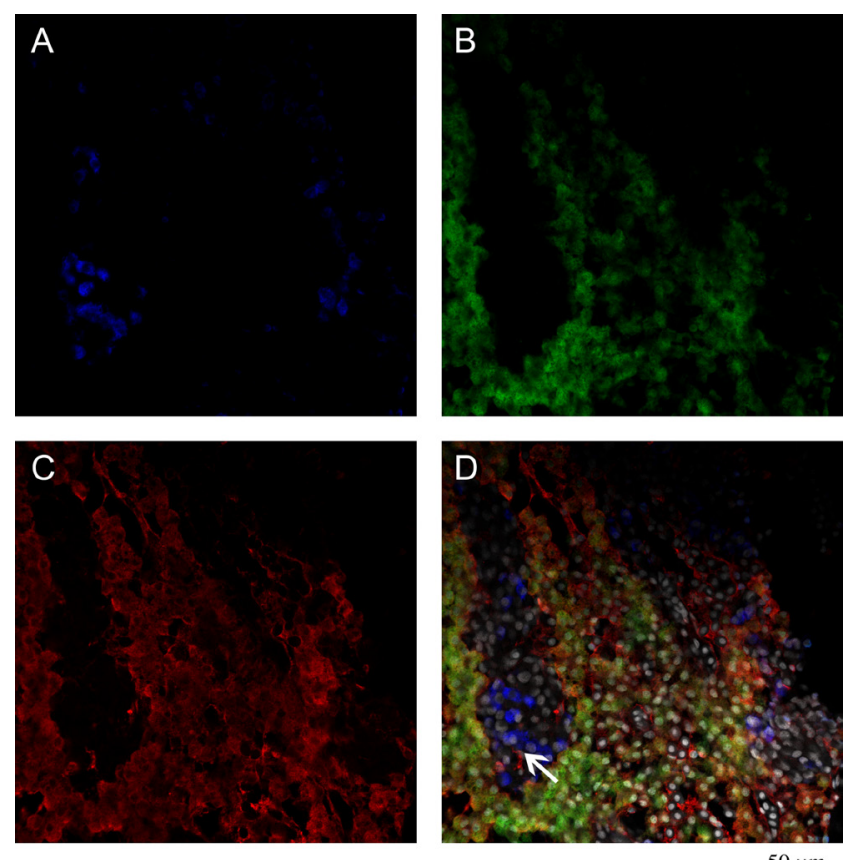

$50 \mu \mathrm{m}$

Figure 7 Differential expression of the $f s h b(\mathrm{~A}), / h b$ (B) transcripts and Lh protein $(C)$ in adult European hake pituitary gland. The picture 7D shows the merging of three pictures and the arrow evidences the presence of Lh protein in the fshb cells.

\section{Localization of fshb and Ihb mRNA and Lhb protein}

The double-labeling FISH and immunofluorescence techniques were coupled to detect the localization of $f_{s h} b$ and Ihb expression simultaneously and Lhb protein on female adult pituitary tissues during reproductive cycle. Contrary to sense probes (data not shown), antisense probes revealed the expression of $f s h b$ and $/ h b$ mRNA in distinct cells in proximal pars distalis (PPD) and in the edge of pars intermedia (PI). fshb and $/ h b$ were expressed mostly in adjacent pituitary cells, but some cells showed co-expression of both hormones (Fig. 6D). Comparing the gene expression of both gonadotropin beta subunits with that of Lhb protein, we observed that the anti-Lhb serum merged completely with the cells positive to Ihb mRNA expression. Also, anti-Lhb stained the cells expressing both hormones, in addition to few cells expressing only fshb (Fig. 7D). During the reproductive cycle, the expression of gonadotropins mRNAs and Lhb protein was always detectable.

\section{Discussion}

The characterization and expression studies of gonadotropin genes have been investigated in several teleost species. As already reported in the 'Introduction' section, the mRNA expression of gonadotropins during the reproductive cycle has not been well defined in teleosts. The main matter is definitely linked to the wide variety of reproductive strategies of different species. For this purpose, the current study was aimed to better understand the functions of Fsh and Lh in the reproduction of European hake, a species with asynchronous ovarian development characterized by different phases of maturation (Sarano 1986, Murua et al. 1998). In the present study, the endocrine control of ovarian maturation of European hake was approached for the first time, by studying gonadotropin molecular characterization, expression and localization in the pituitary gland throughout the seasonal reproductive cycle in wild specimens captured in the Adriatic Sea.

The $f s h b$ and $/ h b$ nucleotide sequences were obtained by the RACE method. Although the approach was successfully performed for $f s h b$, same approach failed to amplify the $5^{\prime}$ terminal part of $/ h b$, obtaining a partial sequence of $509 \mathrm{nt}$. The two nucleotide sequences were used to predict the relative amino acid sequences. Analyzing the Fshb-deduced polypeptide, it had $63 \%$ sequence homology to another gadoid fish, Atlantic cod (Gadus morhua) and 35-59\% identity range to other teleosts. It is notable that the $\mathrm{N}$-glycosylation site conserved the position through teleosts, though in the most of fishes the specific consensus sequence of $\mathrm{N}$-linked glycosylation consists in Asn-X-Ser, whereas in hake was Asn-X-Thr as in chum salmon (Sekine et al. 1989) and in tetrapods. Also like tetrapods and ancient teleosts (Yoshiura et al. 1999, Quérat et al. 2001), the European hake showed two potential N-glycosylation sites in contrast to other modern teleosts. The presence of two sites ensures the biological potencies of the hormone and stabilize the interactions with its receptor (Bousfield et al. 1994). Also as tetrapods and ancient teleosts, European hake showed 12 cysteine residues associated with 'seatbelt' region. The same numbers of cysteine residues were found also in other teleosts, except for siluriformes and cypriniformes, that present an additional residue at the $\mathrm{N}$-terminus, the Cys3 (according to the numbering in tetrapods). The lack of Cys3 could increase the stability on the tertiary structure of the heterodimer (Xing et al. 2004, Levavi-Sivan et al. 2010). Regarding the partial amino acid sequence of Lhb, it had $77 \%$ homology with Atlantic cod and $57-70 \%$ identity range to other fishes. We found nine of the expected twelve cysteine residues that are typical for teleosts, and their position was highly conserved. Together with Fshb protein, the Lhb amino acid sequence was used for the construction of the phylogenetic tree that was inferred from various teleost Fshb and Lhb protein sequences. Both hormones were distinctly separated in independent order and both showed high similarity to respective homolog hormone genes of Atlantic cod, confirming that they belong to Gadiformes order.

The monthly trend of the mean GSI showed two different peaks, one in December and the highest in June, where the reproductive activity was concentrated. The increase of GSI, excluding the spawning period, confirmed that hake spawns continuously throughout the year (Murua \& Motos 2006). 
Considering the expression profiles of gonadotropin genes in the pituitary gland of European hake during their reproductive cycle, the novel finding is consistent with detectable levels of $f_{s} h b$ along all the reproductive phases - from Immature/Regenerating to Actively Spawning period as classified by Brown-Peterson and coworkers (2011). Previous studies concerning the expression pattern of $f s h b$ during gonadal maturation suggested that the hormone is mainly involved in the first phases of the gonadal cycle and the temporal profile of mRNA expression was distinct from that of Ihb, which was expressed especially during the last phases of reproduction (Planas \& Swanson 1995, Tyler et al. 1997, Gomez et al. 1999, Yoshiura et al. 1999, Schmitz et al. 2005). Unlike species with synchronous ovarian development, the European hake displayed high expression of fshb during F2 and F3A phase, suggesting a continuous role of this hormone due to the presence of different oocyte stages into the ovary at the same time. Indeed, although some oocytes are involved in final maturation and ovulation, other oocytes in the same ovary are still in vitellogenesis. A similar trend was detected in other multiple spawners (Gen et al. 2000, Kajimura et al. 2001, Mateos et al. 2003, Weltzien et al. 2003b). Remarking the typical reproductive pattern reported and consistent with other teleost species, the gene expression of $/ h b$ in the pituitary showed a significant peak in F3A as in all teleosts. The low $f_{s} h b$ and $/ h b$ expression in actively spawning stage females (F3B) may be caused by a negative feedback exerted on the gonadotropic cells by the high levels of gonadal steroid hormones (Kajimura et al. 2001), though other authors (Asturiano et al. 2002) evidenced that changes in gonadal hormones could lead to the spermiation and ovulation.

Finally, the present study provided for the first time the information about the specificity of hormone production by gonadotropic cells by combining doublelabeling fluorescent in situ hybridization of $f_{s} h b$ and $/ h b$ with Lhb protein immunofluorescence. The distribution of gonadotropic cells evidenced several differences with other teleosts. Different from So and coworkers (2005) where the cells expressing fshb were arranged as small cell clusters or single cells and Ihb-like large clusters in zebrafish, there was no apparent difference in the distribution pattern between fshb and Ihb cells in European hake, indeed both gonadotrope cell types were arranged like large clusters throughout PPD during all ovarian stages. Although it was difficult to quantitate accurately the numbers of the two types of gonadotropic cells, they seemed to be similar. In addition, Cao and coworkers (2009) detected fshb cells in the middle area of PPD and $/ h b$ in the middle and in periphery of PPD and in PI, whereas in European hake, the $f_{s} h b$ and $/ h b$ cells were homogenously distributed through the whole PPD and in PI. Previous studies in Senegalese sole and Atlantic halibut (Cerdà et al. 2008, Weltzien et al. 2003b) evidenced mainly the $f s h b$ and $/ h b$ expression in distinct gonadotropes of the PPD, although the authors did not exclude the possible presence of the co-expression of both gonadotropins in a single gonadotropic cell. The use of confocal imaging associated with fluorescent labeling allowed us to establish that a limited number of cells co-express both hormones. It is still unclear whether the cells that produced both hormones have always presented such ability or, instead, if this is an acquired function during reproductive cycle. From previous results, Golan and coworkers (2014) found few cells that showed colocalization of Fshb and Lhb proteins in tilapia and zebrafish, hypothesizing that these gonadotropes are bipotent cells that subsequently undergo the differentiation into either $f_{s} h b$ or $/ h b$ cells. In addition to this hypothesis, we suggest that the gonadotropes could have a plasticity that permits changes during lifetime and in turn during different physiological states. The presence of Lhb protein merged mainly with Ihb cells and also in cells expressing both hormones. Surprisingly, it was also recorded in a few fshb cells. As we could not investigate the presence of Fshb protein due to the lack of suitable antibodies, it remains difficult to clarify if the presence of Lhb protein in those few cells is the result of a changing of phenotype or those cells are not completely differentiated.

In conclusion, we have used the European hake, an important commercial species-like model to elucidate the role of Fsh and Lh in species with asynchronous ovary. We report the sequences and molecular information on gonadotropin subunits in European hake. In addition, the specific expression of $f_{s h b}$ and Ihb in different cells in pituitary gland confirmed the gonadotropin localization similar to other teleost fish, but the additional small number of cells that showed co-expression could provide important bases for further investigations on $f s h$ and $/ h$ cell differentiation.

\section{Declaration of interest}

The authors declare that there is no conflict of interest that could be perceived as prejudicing the impartiality of the research reported.

\section{Funding}

Michela Candelma had a grant from COST Office (Food and Agriculture COST Action FA1205: Assessing and improving the quality of aquatic animal gametes to enhance aquatic resources. The need to harmonize and standardize evolving methodologies, and improve transfer from academia to industry; AQUAGAMETE) for this project.

\section{Acknowledgements}

The authors wish to thank the Dr Filippo Domenichetti, and Dr Camilla Croci of Marine Science Institute - CNR and the Captain Giordano and crew of 'Orizzonte' vessel for their 
support in sampling. Also, they are grateful to Susann Burow from Weltzien's laboratory for the use of medaka Lhb antibody in our work.

\section{References}

Asturiano JF, Sorbera L, Ramos J, Kime D, Carrillo M \& Zanuy S 2002 Group-synchronous ovarian development, spawning and spermiation in the European sea bass (Dicentrarchus labrax L.) could be regulated by shifts in gonadal sterodiogenesis. Scientia Marina 66 273-282. (doi:10.3989/scimar.2002.66n3273)

Bousfield G, Perry WM \& Ward DN 1994 Gonadotropins: chemistry and biosynthesis. In The Physiology of Reproduction, edn 5, pp 1749-1792. Eds E Knobil \& JD Neill. New York, NY, USA: Raven Press.

Brown-Peterson NJ, Wyanski DM, Saborido-Rey F, Macewicz BJ \& Lowerre-Barbieri SK 2011 A standardized terminology for describing reproductive development in fishes. Marine and Coastal Fisheries 3 52-70. (doi:10.1080/19425120.2011.555724)

Cao H, Zhou L, Zhang YZ, Wei QW, Chen XH \& Gui JF 2009 Molecular characterization of Chinese sturgeon gonadotropins and cellular distribution in pituitaries of mature and immature individuals. Molecular and Cellular Endocrinology 303 34-42. (doi:10.1016/j. mce.2009.01.015)

Caputo V, Candi G, Colella S \& Arneri E 2001 Reproductive biology of turbot (Psetta maxima) and brill (Scophthalmus rhombus) (Teleostei, Pleuronectiformes) in the Adriatic Sea. Italian Journal of Zoology 68 107-113. (doi:10.1080/11250000109356393)

Cerdà J, Chauvigne F, Agulleiro MJ, Marin E, Halm S, Martinez-Rodriguez G \& Prat F 2008 Molecular cloning of Senegalese sole (Solea senegalensis) follicle-stimulating hormone and luteinizing hormone subunits and expression pattern during spermatogenesis. General and Comparative Endocrinology 156 470-481. (doi:10.1016/j.ygcen.2008.02.006)

Edgar RC 2004 MUSCLE: a multiple sequence alignment method with reduced time and space complexity. BMC Bioinformatics 5113. (doi:10.1186/1471-2105-5-113)

Fontaine R, Affaticati P, Yamamoto K, Jolly C, Bureau C, Baloche S, Gonnet F, Vernier P, Dufour S \& Pasqualini C. 2013 Dopamine inhibits reproduction in female zebrafish. Neuroendocrinology 154 807-818. (doi:10.1210/en.2012-1759)

García Hernández PM, García Ayala A, Zandbergen MA \& Agulleiro B 2002 Investigation into the duality of gonadotropic cells of Mediterranean yellowtail (Seriola dumerilii, Risso 1810): immunocytochemical and ultrastructural studies. General and Comparative Endocrinology $\mathbf{1 2 8}$ 25-35. (doi:10.1016/s0016-6480(02)00052-7)

Gen K, Okuzawa K, Senthilkumaran B, Tanaka H, Moriyama S \& Kagawa H 2000 Unique expression of gonadotropin-I and -II subunit genes in male and female red seabream (Pagrus major) during sexual maturation. Biology of Reproduction 63 308-319. (doi:10.1095/biolreprod63.1.308)

Golan M, Biran J \& Levavi-Sivan B 2014 A novel model for development, organization, and function of gonadotropes in fish pituitary. Frontiers in Endocrinology 5 182. (doi:10.3389/fendo.2014.00182)

Gomez JM, Weil C, Ollitrault M, Le Bail PY, Breton B \& Le Gac F 1999 Growth hormone $(\mathrm{GH})$ and gonadotropin subunit gene expression and pituitary and plasma changes during spermatogenesis and oogenesis in rainbow trout (Oncorhynchus mykiss). General and Comparative Endocrinology 113 413-428. (doi:10.1006/gcen.1998.7222)

Han YS, Liao IC, Huang YS, Tzeng WN \& Yu JYL 2003 Profiles of PGH- $\alpha$, GTH I- $\beta$, and GTH II- $\beta$ mRNA transcript levels at different ovarian stages in the wild female Japanese eel Anguilla japonica. General and Comparative Endocrinology 133 8-16. (doi:10.1016/ S0016-6480(03)00143-6)

Kajimura S, Yoshiura Y, Suzuki M \& Aida K 2001 cDNA cloning of two gonadotropin beta subunits (GTH-Ibeta and -Ilbeta) and their expression profiles during gametogenesis in the Japanese flounder (Paralichthys olivaceus). General and Comparative Endocrinology 122 117-129. (doi:10.1006/gcen.2000.7610)

Levavi-Sivan B, Bogerd J, Mañanós EL, Gómez A \& Lareyre JJ 2010 Perspectives on fish gonadotropins and their receptors. General and Comparative Endocrinology 165 412-437. (doi:10.1016/j. ygcen.2009.07.019)
Mateos J, Mañanós E, Martinez-Rodriguez G, Carrillo M, Querat B \& Zanuy S 2003 Molecular characterization of sea bass gonadotropin subunits $(\alpha, \mathrm{FSH} \beta$, and $\mathrm{LH} \beta$ ) and their expression during the reproductive cycle. General and Comparative Endocrinology 133 216-232. (doi:10.1016/S0016-6480(03)00164-3)

Mittelholzer C, Andersson E, Taranger GL, Karlsen $\varnothing$ \& Norberg B 2009 Quantification of gonadotropin subunits $\mathrm{GP} \alpha, \mathrm{FSH} \beta$, and LH $\beta$ mRNA expression from Atlantic cod (Gadus morhua) throughout a reproductive cycle. Comparative Biochemistry and Physiology: $B$ Biochemistry and Molecular Biology 153 288-295. (doi:10.1016/j. cbpb.2009.03.011)

Murua H \& Motos L 2006 Reproductive strategy and spawning activity of the European hake Merluccius merluccius (L.) in the Bay of Biscay. Journal of Fish Biology 69 1288-1303. (doi:10.1111/j.1095-8649.2006.01169.x)

Murua H, Motos L \& Lucio P 1998 Reproductive modality and batch fecundity of the European hake (Merluccius merluccius L.) in the Bay of Biscay. California Cooperative Oceanic Fisheries Investigations Reports 39 196-203.

Nagahama Y 1994 Endocrine regulation of gametogenesis in fish. International Journal of Developmental Biology 38 217-229.

Nakane PK 1970 Classifications of anterior pituitary cell types with immunoenzyme histochemistry. Journal of Histochemistry and Cytochemistry 18 9-20. (doi:10.1177/18.1.9)

Nyuji M, Selvaraj S, Kitano H, Ohga H, Yoneda M, Shimizu A, Kaneko K, Yamaguchi A \& Matsuyama M 2012 Changes in the expression of pituitary gonadotropin subunits during reproductive cycle of multiple spawning female chub mackerel Scomber japonicus. Fish Physiology and Biochemistry 38 883-897. (doi:10.1007/s10695-011-9576-y)

Planas JV \& Swanson P 1995 Maturation-associated changes in the response of the salmon testis to the steroidogenic actions of gonadotropins (GTH I and GTH II) in vitro. Biology of Reproduction 52 697-704. (doi:10.1095/biolreprod52.3.697)

Quérat B, Tonnerre-Doncarli C, Géniès F \& Salmon C 2001 Duality of gonadotropins in gnathostomes. General and Comparative Endocrinology 124 308-314. (doi:10.1006/gcen.2001.7715)

Raingeard D, Bilbao E, Sáez-Morquecho C, de Cerio OD, Orbea A, Cancio I \& Cajaraville MP 2009 Cloning and transcription of nuclear receptors and other toxicologically relevant genes, and exposure biomarkers in European hake (Merluccius merluccius) after the Prestige oil spill. Marine Genomics 2 201-213. (doi:10.1016/j.margen.2009.10.004)

Santangeli S, Maradonna F, Gioacchini G, Cobellis G, Piccinetti CC, Dalla Valle L \& Carnevali O 2016 BPA-induced deregulation of epigenetic patterns: effects on female zebrafish reproduction. Scientific Reports 6 21982. (doi:10.1038/srep21982)

Sarano F 1986 Ovarian cycle of the hake, Merluccius merluccius, as a partial spawner fish. Revue Des Travaux de l'Institut Des Pêches Maritimes 48 65-76.

Schindelin J, Arganda-Carreras I, Frise E, Kaynig V, Longair M, Pietzsch T, Preibisch S, Rueden C, Saalfeld S, Schmid B et al. 2012 Fiji: an opensource platform for biological-image analysis. Nature Methods $\mathbf{9}$ 676-682. (doi:10.1038/nmeth.2019)

Schmitz M, Aroua S, Vidal B, Le Belle N, Elie P \& Dufour S 2005 Differential regulation of luteinizing hormone and follicle-stimulating hormone expression during ovarian development and under sexual steroid feedback in the European eel. Neuroendocrinology 81 107-119. (doi:10.1159/000086404)

Sekine S, Akiko S, Hiromichi I, Hiroshi K \& Seiga I 1989 Molecular cloning and sequence analysis of chum salmon gonadotropin cDNAs. PNAS $\mathbf{8 6}$ 8645-8649. (doi:10.1073/pnas.86.22.8645)

Sievers F, Wilm A, Dineen D, Gibson TJ, Karplus K, Li W, Lopez R, McWilliam H, Remmert M, Söding J et al. 2011 Fast, scalable generation of high-quality protein multiple sequence alignments using Clustal Omega. Molecular Systems Biology 7 539. (doi:10.1038/ msb.2011.75)

So W, Kwok H \& Ge W 2005 Zebrafish gonadotropins and their receptors: II. Cloning and characterization of zebrafish follicle-stimulating hormone and luteinizing hormone subunits. Their spatial-temporal expression patterns and receptor specificity. Biology of Reproduction 72 1382-1396. (doi:10.1095/biolreprod.104.038216)

Swanson P, Dickey JT \& Campbell B 2003 Biochemistry and physiology of fish gonadotropins. Fish Physiology and Biochemistry 28 53-59. (doi:10.1023/B:FISH.0000030476.73360.07) 
Tamura K, Stecher G, Peterson D, Filipski A \& Kumar S 2013 MEGA6: molecular evolutionary genetics analysis version 6.0. Molecular Biology and Evolution 30 2725-2729. (doi:10.1093/molbev/mst197)

Tyler CR \& Sumpter JP 1996 Oocyte growth and development in teleosts. Reviews in Fish Biology and Fisheries 6 287-318. (doi:10.1007/ BF00122584)

Tyler C, Pottinger T \& Coward K 1997 Salmonid follicle-stimulating hormone (GtH I) mediates vitellogenic development of oocytes in the rainbow trout, Oncorhynchus mykiss. Biology of Reproduction 57 1238-1244. (doi:10.1095/biolreprod57.5.1238)

Weltzien F-A, Norberg B, Helvik JV, Andersen $\varnothing$, Swanson P \& Andersson E 2003a Identification and localization of eight distinct hormone-producing cell types in the pituitary of male Atlantic halibut (Hippoglossus hippoglossus L.). Comparative Biochemistry and Physiology: A Molecular and Integrative Physiology 134 315-327. (doi:10.1016/S1095-6433(02)00266-0)

Weltzien F-A, Kobayashi T, Andersson E, Norberg B \& Anderson O 2003b Molecular characterization and expression of FSH beta, LH beta, and common alpha-subunit in male Atlantic halibut (Hippoglossus hippoglossus). General and Comparative Endocrinology 131 87-96. (doi:10.1016/S0016-6480(02)00606-8)

Weltzien F-A, Andersson E, Andersen $\varnothing$, Shalchian-Tabrizi K \& Norberg B 2004 The brain-pituitary-gonad axis in male teleosts, with special emphasis on flatfish (Pleuronectiformes). Comparative Biochemistry and Physiology: A Molecular and Integrative Physiology 137 447-477. (doi:10.1016/j.cbpb.2003.11.007)

Weltzien F-A, Hildahl J, Hodne K, Okubo K \& Haug TM 2014 Embryonic development of gonadotrope cells and gonadotropic hormones - lessons from model fish. Molecular and Cellular Endocrinology 385 18-27. (doi:10.1016/j.mce.2013.10.016)

Yoshiura Y, Suetake H \& Aida K 1999 Duality of gonadotropin in a primitive teleost, Japanese eel (Anguilla japonica). General and Comparative Endocrinology 114 121-131. (doi:10.1006/gcen.1998.7242)

Zohar Y, Munoz-Cueto JA, Elizur A \& Kah O 2010 Neuroendocrinology of reproduction in teleost fish. General and Comparative Endocrinology 165 438-455. (doi:10.1016/j.ygcen.2009.04.017)

Xing Y, Myers RV, Cao D, Lin W, Jiang M, Bernard MP \& Moyle WR 2004 Glycoprotein hormone assembly in the endoplasmic reticulum: III. The seatbelt and its latch site determine the assembly pathway. Journal of Biological Chemistry 279 35449-35457. (doi:10.1074/jbc.M403054200)

Received 18 July 2016

First decision 6 October 2016

Revised manuscript received 27 October 2016

Accepted 1 November 2016 